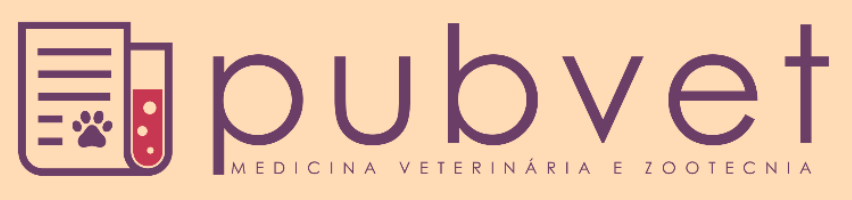

https://doi.org/10.31533/pubvet.v15n10a947.1-4

\title{
Osteossarcoma apendicular em felino: Relato de caso
}

\author{
Suélen Letícia dos Santos $^{1^{*}}{ }^{\bullet}$, Bruna Bertin Fenner ${ }^{1}{ }^{\bullet}$, Patrícia Roberta Weber ${ }^{1} \bullet$, Luciana \\ Lígia Guidolin $^{1}$, Natali Gabriela Gauer ${ }^{2} \bullet$
}

${ }^{1}$ Médica Veterinária, Clínica Veterinária Luciana Guidolin, Caxias do Sul-RS Brasil.

${ }^{2}$ Graduanda em Medicina Veterinária, Universidade de Caxias do Sul, Caxias do Sul-RS Brasil.

*Autor para correspondência: medvetsuelenleticia@gmail.com

\begin{abstract}
Resumo. As neoplasias ósseas primárias são incomuns em gatos, sendo o osteossarcoma entre elas a mais frequente observada, geralmente em animais de meia idade e idosos. Esta neoplasia acomete o esqueleto apendicular, porém o esqueleto axial também pode ser afetado, sendo os ossos da cabeça e da pélvis os locais mais frequentes de lesões. O presente relato descreve um gato de onze anos com aumento de volume em membro pélvico direito, algia e claudicação. O diagnóstico presuntivo é realizado através do exame clínico, radiográfico e confirmação do histopatológico.
\end{abstract}

Palavras-chave: Felino, neoplasia, apendicular, osteossarcoma

\section{Appendicular osteosarcoma in a feline: Case report}

\begin{abstract}
The neoplasms bone primary is uncommon in cats, with o Osteosarcoma among them being the most frequent observed, usually in middle-aged and elderly animals. This neoplasm affects the appendicular skeleton, but the axial skeleton can also be affected, with the bones of the head and pelvis being the most frequent sites of injuries. The present report is an eleven-year-old cat trial with swelling in the right pelvic limb, pain and lameness. The presumptive diagnosis is made through clinical, radiographic examination and confirmation by histopathology.
\end{abstract}

Keywords: Cats, neoplasms, appendicular, osteosarcoma

\section{Introdução}

Os tumores ósseos primários são raros em felinos, observando baixa incidência destas neoplasias, mesmo assim o osteossarcoma é o mais comum, responsável por 70\% a 80\% dos tumores ósseos em felinos, tendo preferência pelo esqueleto apendicular, afetando gatos adultos ou idosos (Kihara et al., 2019; Oliveira \& Silveira, 2008). Segundo Daleck et al. (2002) as alterações radiográficas na área afetada, são semelhantes ao osteossarcoma canino, com processos líticos e proliferativo, porém a lise cortical é o achado mais frequente sendo o suficiente para promover áreas de descontinuidade do córtex, causando fraturas espontâneas. O diagnóstico definitivo é obtido por meio de sinais clínicos, localização

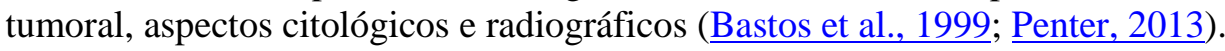

Na espécie felina apresenta baixo índice de metástases proveniente de tumores ósseos, e a amputação representa o método mais eficiente de tratamento em gatos. Quando há casos de metástases estas geralmente desenvolvem-se nos pulmões, linfonodos regionais e rins. Gatos com osteossarcoma apendicular têm taxa de metástase variando entre 5\% e 10\%, com tempo de sobrevida média de 64 meses (Dimopoulou et al., 2008). Estes achados sugerem que o osteossarcoma felino é menos agressivo do que o canino, a espécie felina apresenta baixo índice de metástases proveniente de tumores ósseos como o osteossarcoma (Heldmann et al., 2000). 
$\mathrm{Na}$ literatura relatos de osteossarcoma apendicular em felino são pouco comuns. Este trabalho tem como objetivo relatar caso clínico de osteossarcoma apendicular em um felino e revisar os aspectos mais importantes desta neoplasia, bem como as possibilidades de tratamento.

\section{Relato de caso}

Foi atendido na Clínica Veterinária Luciana Guidolin, na cidade de Caxias do Sul- RS, um felino, macho, castrado, sem raça definida, com aproximadamente 11 anos de idade. O tutor relatou que o paciente já apresentava desconforto no membro posterior direito há alguns meses sendo que anteriormente procurou atendimento médico veterinário, e nesta ocasião foi diagnosticado com artrose e tratado com antiinflamatórios não esteroides por longo período de tempo. O tutor procurou o atendimento clínico, pois o animal passou a não apoiar o membro, bem como a manipulação do mesmo por extrema algia.

No exame clínico geral, o animal apresentou mucosas normocoradas, frequência cardíaca e respiratória e temperatura retal dentro dos valores de referência, linfonodo poplíteo direito aumentado em comparação ao esquerdo. Também se percebeu aumento de volume na articulação fêmur-tíbiopatelar direita com grau elevado de dor. $\mathrm{O}$ animal foi submetido a internação para a realização de exames complementares e analgesia adequada.

Foram realizados exames de hemograma e bioquímica sérica, os quais apresentaram leucocitose por neutrofilia, creatinina abaixo dos valores de referência (VR) e as enzimas ALT e AST levemente acima das dos VR. O exame radiográfico do membro acometido apresentou aumento de volume na região proximal da tíbia e distal de fêmur, com perda da definição corticomedular e de densidade óssea, além de fratura em região, imagem sugestiva de fratura patológica (Figura 1). Foi realizado também estudo radiográfico de tórax, onde não foram observadas alterações. Neste momento, o principal diagnóstico diferencial foi fratura patológica decorrente de tumor ósseo.

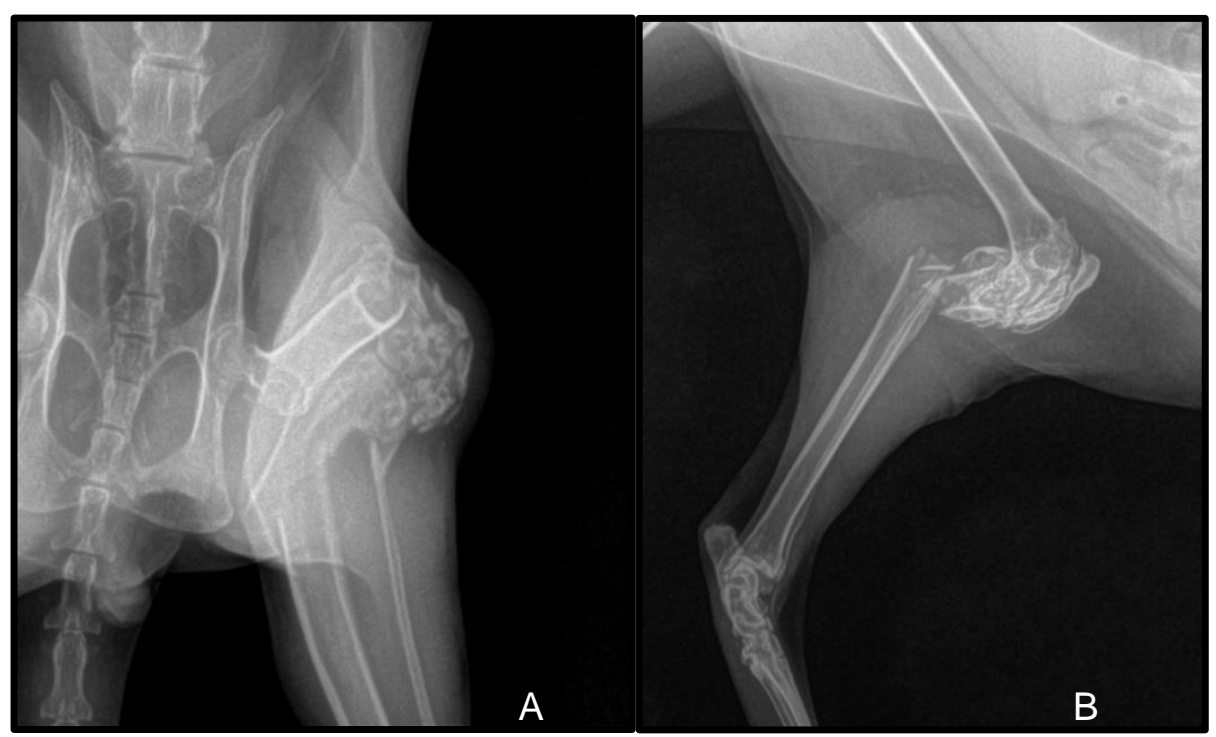

Figura 1. Posicionamento ventro-dorsal do membro pélvico direito, com aumento de volume na região proximal da tíbia e distal de fêmur (A), e posicionamento latero-lateral do membro pélvico direito com fratura $(\mathrm{B})$.

Como forma de tratamento, foi optado pela amputação alta do membro posterior direito. O membro foi encaminhado para análise histopatológica. As medicações administradas no período pós-operatório foram metadona $0,3 \mathrm{mg} / \mathrm{kg}$, a cada seis horas, dipirona sódica, $12,5 \mathrm{mg} / \mathrm{kg}$, duas vezes ao dia, robenacoxib, $2 \mathrm{mg} / \mathrm{kg}$, uma vez ao dia e cefalotina, $20 \mathrm{mg} / \mathrm{kg}$, duas vezes ao dia.

Os achados histopatológicos foram compatíveis com osteossarcoma apendicular. O paciente retornou para revisão e retirada das suturas externas após 10 dias do procedimento, apresentando-se em bom estado geral, sem alterações no exame clínico geral. O tutor referiu que o felino já estava se adaptando à ausência do membro. 


\section{Discussão}

A idade média dos gatos que apresentam osteossarcoma varia de oito a dez anos e não foi identificada predisposição racial ou sexual (Fossum, 2014). A procura por atendimento veterinário se dá, na maioria dos casos, devido à claudicação ou inchaço no membro acometido (Nelson \& Couto, 2015). Os tutores do paciente mencionado acima procuraram atendimento devido à claudicação e a dor que o mesmo apresentava, os quais são os sinais mais comuns encontrados em pacientes com neoplasias ósseas.

Um estudo contendo 22 casos de felinos diagnosticados com osteossarcoma mostrou que a maior prevalência é em esqueleto apendicular (Bitetto et al., 1987). Os osteossarcomas apendiculares ocorrem principalmente nas metáfises distais de rádio, distal de fêmur e proximal de úmero, embora outras regiões podem ser acometidas (Nelson \& Couto, 2015). O felino citado acima apresentava alterações clínicas e radiográficas em esqueleto apendicular, mais especificamente em metáfise distal de fêmur, bem como na maior parte dos casos citados na literatura.

O osteossarcoma é a neoplasia óssea de maior incidência em gatos (70-80\%), sendo incomum a presença de metástases. O tempo médio de sobrevida de um felino com essa neoplasia varia de 12 a 50 meses (Fossum, 2014). Nos cães a incidência de metástases é extremamente comum e ocorre de forma rápida, já em gatos a taxa metastática é muito menor e tem sido relatada entre 8 a 16\% (Baum et al., 2018). Não foram evidenciados presença de metástases durante a evolução do quadro clínico.

Embora não se saiba a causa do desenvolvimento do tumor ósseo neste paciente, uma das causas de formação de neoplasias encontra-se a inflamação crônica, em geral, quanto mais a inflamação persistir maior o risco de desenvolvimento de neoplasias (Shacter \& Weitzman, 2002). Os tutores relataram que o paciente havia sido diagnosticado anteriormente com artrose, o que justificaria uma inflamação crônica.

Como medida de tratamento, a amputação do membro afetado é o tratamento de eleição e devido à baixa taxa metastática em felinos a amputação pode ser, na maioria dos casos, uma medida curativa em casos de osteossarcoma apendicular (Nakata et al., 2017).

\section{Conclusão}

O osteossarcoma felino é uma neoplasia maligna, porém apresenta comportamento biológico menos agressivo em relação ao osteossarcoma canino, apresentando baixo índice de metástase. Entretanto, o prognóstico se mantém reservado dependendo da localização, tempo de evolução e alterações anatômicas.

\section{Referências bibliográficas}

Bastos, T. M. M., Serafini, O. A., Barrios, C. H. E., \& Velasco, P. A. (1999). Osteossarcoma: tratamento e fatores prognósticos. Revista Brasileira de Ortopedia, 34(1), 59-62.

Baum, J. I., Skinner, O. T., \& Boston, S. E. (2018). Fracture-associated osteosarcoma of the femur in a cat. The Canadian Veterinary Journal, 59(10), 1096.

Bitetto, W. V, Patnaik, A. K., Schrader, S. C., \& Mooney, S. C. (1987). Osteosarcoma in cats: 22 cases (1974-1984). Journal of the American Veterinary Medical Association, 190(1), 91-93.

Daleck, C. R., Fonseca, C. S., \& Canola, J. C. (2002). Osteossarcoma canino-revisão. Revista de Educação Continuada Em Medicina Veterinária e Zootecnia, 5(3), 233-242.

Dimopoulou, M., Kirpensteijn, J., Moens, H., \& Kik, M. (2008). Histologic prognosticators in feline osteosarcoma: a comparison with phenotypically similar canine osteosarcoma. Veterinary Surgery, $37(5), 466-471$.

Fossum, T. W. (2014). Cirurgia de pequenos animais (4th ed., Vol. 1). Elsevier Brasil.

Heldmann, E., Anderson, M. A., \& Wagner-Mann, C. (2000). Feline osteosarcoma: 145 cases (19901995). Journal of the American Animal Hospital Association, 36(6), 518-521.

Kihara, M. T., Sembenelli, G., Jark, P. C., Avante, M. L., \& Canola, J. C. (2019). Osteossarcoma em sacro de felino doméstico: relato de caso. Revista de Educação Continuada Em Medicina Veterinária e Zootecnia Do CRMV-SP, 17(1), 79. 
Nakata, K., Miura, H., Sakai, H., Mori, T., Shibata, S., Nishida, H., Maeda, S., \& Kamishina, H. (2017). Vertebral replacement for the treatment of vertebral osteosarcoma in a cat. Journal of Veterinary Medical Science, 79(6), 999-1002. https://doi.org/10.1292/jvms.17-0142.

Nelson, R. W., \& Couto, C. G. (2015). Medicina interna de pequenos animais (Issue 1). Elsevier Editora.

Oliveira, F., \& Silveira, P. R. (2008). Osteossarcoma em cães (revisão de literatura). Revista Científica Eletrônica de Medicina Veterinária, 4(11), 1-7.

Penter, C. D. (2013). Estudo retrospectivo da sobrevida de cães com osteossarcoma apendicular submetidos à amputação de membro com ou sem quimioterapia adjuvante. In Faculdade de Medicina Veterinária. Universidade Federal do Rio Grande do Sul.

Shacter, E., \& Weitzman, S. A. (2002). Chronic inflammation and cancer. Oncology, 16(2), 217-226.

Histórico do artigo:

Recebido: 16 de junho de 2021

Aprovado: 18 de julho de 2021
Licenciamento: Este artigo é publicado na modalidade Acesso Aberto sob a licença Creative Commons Atribuição 4.0 (CC-BY 4.0), a qual permite uso irrestrito, distribuição, reprodução em qualquer meio, desde que o autor e a fonte sejam devidamente creditados. 